http://jmscr.igmpublication.org/home/ ISSN (e)-2347-176x ISSN (p) 2455-0450 crossref DOI: https://dx.doi.org/10.18535/jmscr/v8i7.18

\title{
Clinico Microbiological Spectrum of Diabetic Foot Ulcer with Multidrug Resistant Organisms at Tertiary Care Hospital, Jaipur
}

\author{
Authors \\ Kavita Mourya ${ }^{1}$, Rajni Sharma ${ }^{2 *}$, Aruna Vyas ${ }^{3}$, Hari Om Khoja ${ }^{4}$, Nitya Vyas ${ }^{5}$ \\ 1,2,3,5 Department of Microbiology, SMS Medical College, Jaipur, Rajasthan \\ ${ }^{4}$ Department of Surgery, SMS Medical College, Jaipur, Rajasthan \\ *Corresponding Author \\ Rajni Sharma \\ SMS Medical College, Jaipur, Rajasthan, India
}

\begin{abstract}
Background: Diabetes is one of the major health problems that have become a big burden in all over the world. Amongst the diabetic population, about 8-20\% experience foot ulcer in life time. DFIs are predominantly polymicrobial and multidrug-resistant (MDR) with the ability to form biofilm, which is an important virulence factor and results in treatment failure.

Objective: To determine the bacteriological profile and susceptibility pattern of organisms and to assess the magnitude of infection by Multidrug resistant organisms (MDRO'S) like Extended spectrum beta lactamase (ESBL) and Methicillin- resistant Staphylococcus aureus (MRSA)

Materials and Methods: A total of 73 pus and exudates sample were collected from diabetic foot patients. Specimens were collected with a sterile swab stick from each patient. Significant isolates were identified by conventional methods according to the standard laboratory protocol. The antibiotic sensitivity test along with screening for MRSA and ESBL producing GNB were done.

Results: The maximum number of diabetic foot cases 30(46.15\%) were seen between age of 51-60 years. A total of 90 organisms were isolated from 65 clinical samples out of which 65(68.39\%) were gram negative bacilli and 25(31.56\%) gram positive cocci. Pseudomonas species (25.65\%) was predominant among gram negative bacilli and Staphylococcus aureus (16.84\%) was the predominant among gram positive cocci. Gram negative organisms showed highest sensitivity to Polymixin B (100\%), Gram positive organisms showed highest sensitivity to Vancomycin (100\%). Out of 65 isolates 16(24.6\%) were ESBL producers. Out of 16 isolates 7(43.7\%) were MRSA. Multidrug resistance was seen in $88.8 \%$ of isolates.

Conclusion: Early identification of the risk factors and timely institution of appropriate treatment indispensable to avoid amputations. There is a need for continuous surveillance of resistant bacteria to provide the basis for empirical therapy and reduce the risk of complications.

Keywords: Diabetic foot ulcers, Extended spectrum beta lactamase, Methicillin- resistant Staphylococcus aureus, Multidrug resistant organisms.
\end{abstract}

\section{Introduction}

Diabetes is one of the major health problems that have become a big burden in all over the world.
Diabetes mellitus (DM) is a serious and complex illness that affects almost every vital organ in the body. There are approximately 415 million people 
worldwide suffering from diabetes. It has been estimated that this number will increase to 642 million by $2040^{1}$.

Amongst the diabetic population, about $8-20 \%$ experience foot ulcer in life time. It is one of the most common causes of hospital admissions in diabetics. Diabetic foot ulcers have $15-45 \%$ higher risk of amputation of limb as compared to foot ulcers secondary to other aetiologies ${ }^{2}$. Diabetic foot involvement including infections and foot ulcers are one of the frequently seen and disabling complications of diabetes leading to significant morbidity and mortality ${ }^{2-4}$.

Diabetic neuropathy and micro or macro ischemia are the two main risk factors that cause diabetic foot ulcer (DFU). Impaired microvascular circulation limits the access of phagocytic cells to infected area, and this result in poor concentration of antibiotics in infected tissue . $^{5}$

DFIs are predominantly polymicrobial and multidrug-resistant (MDR) with the ability to form biofilm, which is an important virulence factor and results in treatment failure ${ }^{6}$.

Diabetic foot infections are often polymicrobial. Escherichia coli, Proteus spp., Pseudomonas spp., Staphylococcus aureus and Enterococcus spp are the most frequent pathogens contributing to progressive and widespread tissue destruction. Methicillin-resistant Staphylococcus aureus (MRSA) has been commonly isolated from 10$40 \%$ of the diabetic wounds ${ }^{3,4}$.

Infection with MDR pathogens is also responsible for the increased duration of hospitalization, cost of management, morbidity and mortality of the diabetic patients ${ }^{5,7,8}$. Therefore this study has been performed to determine the common etiological agents of diabetic foot infections and in vitro susceptibility to routinely used antibiotics and to assess the magnitude of infection by Multidrug resistant organisms (MDRO'S) like Extended spectrum beta lactamase (ESBL) and Methicillinresistant Staphylococcus aureus and their correlation with type of ulcer and severity of diabetes.

\section{Materials and Methods}

Study Population: A total of 73 pus and exudates sample were collected from diabetic foot patients attending hospital both OPD and IPD were included in the study. Specimens were collected from under the margin of the ulcer and base of the ulcer with a sterile swab stick from each patient in a sterile container under aseptic conditions by standard protocols. The study has been carried out at department of Microbiology, S.M.S Medical College Jaipur.

\section{Inclusion criteria:}

i) Diabetic patients complicated by diabetic foot ulcer

ii) Patient who gives a valid consent.

\section{Exclusion criteria:}

i) Diabetic patients without complicated by diabetic foot ulcer

\section{Sample Processing}

Samples were taken using two swab sticks, first swab stick subjected to gram staining to observe for the presence of pus cells and organisms. From second swab stick, sample was inoculated on Nutrient agar, Blood agar, Mac-Conkey agar and Thioglycollate broth. The inoculated media were incubated aerobically at $37^{\circ} \mathrm{C}$ for $18-24$ hours and were observed for growth.

\section{Methodology}

Significant isolates were identified by conventional methods according to the standard laboratory protocol, including colony morphology, gram staining and biochemical reactions. All gram negative bacilli were identified to species level by their characteristic appearances on the media, Gram's stain, Oxidase test, Motility and biochemical reactions as per standard laboratory protocol. All gram positive organisms were identified to species level by their characteristic appearances on the media, Gram's stain, and Catalase test followed by Coagulase test. Enterococcus was identified by Bile Esculin disc test and it was also confirmed by Salt tolerance test $(6.5 \% \mathrm{NaCl}$.) 


\section{Antimicrobial Susceptibility Testing}

The antibiotic sensitivity test was performed by modified Kirby Bauer disc diffusion technique ${ }^{9}$ with commercially available Hi-Media antibiotic discs according to Central Laboratory Standard Institute (CLSI) guidelines on Mueller Hinton agar plates. The antibiotics which were used in our study were based on the standard protocol of the hospital and departmental policies as per CLSI guideline $^{10}$.

\section{Detection of extended spectrum beta- lactamases $^{11}$}

Detection of extended spectrum beta- lactamases was done according to CLSI guidelines by two methods Phenotypic Confirmatory Disc Diffusion Test (PCDDT) and Double Disc Synergy Test (DDST)

\section{Phenotypic confirmatory disc diffusion test (PCDDT)}

Lawn culture of isolate was made on Muller Hinton Agar (MHA) plate; discs of ceftazidime and ceftazidime + Clavulanic acid were placed on the surface of MHA and incubate overnight at $37^{\circ} \mathrm{C}$. An increase of $\geq 5 \mathrm{~mm}$ in zone diameter of ceftazidime + Clavulanic acid in comparison to the zone diameter of ceftazidime alone confirmed the organisms to be ESBL producers

\section{ESBL detection by Double Disc Synergy Test (DDST)-}

Lawn culture of isolate was made on Muller Hinton Agar (MHA) plate. Disc of ceftazidime $(30 \mu \mathrm{g})$, cefotaxime $(30 \mu \mathrm{g})$ and co-amoxyclav

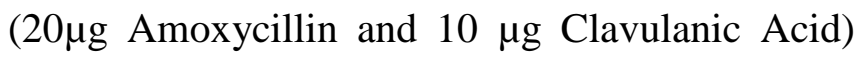
were placed at a distance of $20 \mathrm{~mm}$ from centre to centre in a straight line, with co-amoxyclav disc in the middle. The plate was incubated aerobically overnight and the results were read on the following day. Isolates which shows an enlargement of the zone of inhibition greater than $5 \mathrm{~mm}$ on the co-amoxyclav side of the disc compared to the result seen on the side without co-amoxyclav was confirmed as ESBL producers. ESBL production was interpreted if the inhibition zone around the test antibiotic disc increased towards the co-amoxyclav disc.
Screening of MRSA was done by cefoxitin disc diffusion test: All strains were tested with $30 \mu \mathrm{g}$ cefoxitin discs (Hi-Media) on Mueller-Hinton agar plates ${ }^{12}$. The bacterial suspension for each strain was adjusted to $0.5 \mathrm{McFarland}$. The zone of inhibition was calculated after 16-18 hr incubation at $35{ }^{\circ} \mathrm{C}$. Zone size were defined according to CLSI criteria (23)(24): susceptible, $\geq 22 \mathrm{~mm}$; resistant, $\leq 21 \mathrm{~mm}$. ATCC $25923 \mathrm{MSSA}$ was used as negative control.

Statistical Analysis: The qualitative data were expressed in proportion and percentages and the quantitative data expressed as mean and standard deviations. The difference in proportion was analyzed by using chi square test. Significance levels for tests were determined as $95 \%(\mathrm{P}<0.05)$

\section{Results}

A total of 73 clinically suspected cases of diabetic foot ulcer were enrolled in our study among that $65(89.04 \%)$ were significant growth and 03 $(4.1 \%)$ were sterile while contaminants grown in $05(6.8 \%)$ samples. Out of 65 significant growth $42(64.61 \%)$ were male while $23(35.38 \%)$ were female. The maximum number of diabetic foot cases 30(46.15\%) were seen between age of 5160 years of age followed by elderly people $\geq 60$ years of age $(32.30 \%)$ and more number of cases seen in patients with duration of 4-8 weeks of foot ulcer. According to Wagener's classification the maximum number of cases were observed in Grade 2 of diabetic foot ulcer 24(36.9\%) followed by 16 cases $(24.6 \%)$ in Grade 3 of diabetic foot ulcer.

Out of 65 cases $42(64.61 \%)$ were monomicrobial growth and $23(35.38 \%)$ were polymicrobial growth. A total of 90 organisms were isolated from 65 clinical samples out of which $65(68.39 \%$ ) were gram negative bacilli and $25(31.56 \%)$ gram positive cocci. Pseudomonas species (25.65\%) was predominant among gram negative bacilli and Staphylococcus aureus (16.84\%) was the predominant among gram positive cocci.

Out of 90 isolates 80 were resistant to 3 or more classes of drugs which accounts for $88.8 \%$ of 
MDRO. Among gram negative organisms 16 out of $65(24.6 \%)$ were ESBL producers. Most of them were Proteus species and Enterobacter species while Methicillin resistant Staphylococcus aureus was reported in $43.7 \%$

Gram negative organisms showed highest sensitivity to Polymixin B (100\%), Tigecyclin (100\%) followed by Meropenem(69.2\%)They showed least sensitivity to amikacin (15\%).

Pseudomaonas species showed highest sensitivity to Colistin (100\%), followed by Cefepime $(42.66 \%)$, while the least sensitive was Ciprofloxacin $(20.8 \%)$.

Gram positive organisms showed highest sensitivity to Vancomycin (100\%) followed by
Doxycyciline (93.7\%) and Linezolid (89.2\%) They showed least sensitivity to ciprofloxacin (12.5\%)

Among gram negative organisms out of 65 isolates 16(24.6\%) were ESBL producers. Most of them were Proteus species and Enterobacter species. Among the Staphylococcus aureus, out of 16 isolates $7(43.7 \%)$ were MRSA. The MRSA displayed high level of resistance to Erythromycin (88\%), Penicillin (75\%) and Quinolones (88\%).

Multidrug resistance was seen in $88.8 \%$ of isolates predominantly occurring in Acinetobacter species, Proteus species and Escherichia coli.

Table 1 Total number of sample tested under study

\begin{tabular}{|l|c|c|}
\hline Samples & Number (n=73) & Percentage (\%) \\
\hline Growth Positive & 65 & $89.04 \%$ \\
\hline Sterile & 3 & $4.1 \%$ \\
\hline Contamination & 5 & $6.8 \%$ \\
\hline Total & 73 & $100 \%$ \\
\hline
\end{tabular}

Table 2 Duration of Diabetic Foot Ulcer under Study

\begin{tabular}{|c|c|c|}
\hline $\begin{array}{l}\text { Duration of Diabetic } \\
\text { foot ulcer }\end{array}$ & $\begin{array}{l}\text { No. of Cases } \\
(n=65)\end{array}$ & $\begin{array}{c}\text { Percentage } \\
(\%)\end{array}$ \\
\hline $2-4$ weeks & 21 & $32.30 \%$ \\
\hline 4-8weeks & 30 & $46.15 \%$ \\
\hline $8-12$ weeks & 9 & $13.84 \%$ \\
\hline$>12$ weeks & 5 & $7.69 \%$ \\
\hline
\end{tabular}

Table 3 Distribution of Bacteria in Positive Culture $(n=95)$

\begin{tabular}{|l|c|c|}
\hline Gram negative Bacteria & Number $(\mathbf{n = 6 5})$ & Percentage (\%) \\
\hline Pseudomonas spp & 24 & $25.26 \%$ \\
\hline Escherichia coli & 13 & $13.68 \%$ \\
\hline Enterobacter spp & 12 & $12.63 \%$ \\
\hline Proteus spp & 07 & $7.36 \%$ \\
\hline Acinetobacter spp & 04 & $4.21 \%$ \\
\hline Citrobacter spp & 02 & $2.10 \%$ \\
\hline Klebsiella spp & 02 & $2.10 \%$ \\
\hline Burkholderia spp & 01 & $1.05 \%$ \\
\hline Gram positive Bacteria & $\mathbf{( n = 3 0 )}$ & \\
\hline Staphylococcus aureus & 16 & $16.84 \%$ \\
\hline Enterococcus spp & 5 & $5.26 \%$ \\
\hline Micrococcus species & 5 & $5.26 \%$ \\
\hline CONS & 3 & $3.15 \%$ \\
\hline Streptococcus spp & 1 & $1.05 \%$ \\
\hline
\end{tabular}


Table 4 Antibiotic Sensitivity of Gram Negative Organisms

\begin{tabular}{|l|c|c|c|c|c|}
\hline & \multicolumn{5}{|c|}{ Organisms(n=65) } \\
\hline Antibiotics & $\begin{array}{c}\text { Escherichia } \\
\text { coli (n=13) }\end{array}$ & $\begin{array}{c}\text { Enterobacter } \\
\text { spp (n=12) }\end{array}$ & $\begin{array}{c}\text { Pseudomonas } \\
\text { spp (n=24) }\end{array}$ & $\begin{array}{c}\text { Proteus spp } \\
\text { (n=7) }\end{array}$ & $\begin{array}{c}\text { Acinetobacter } \\
\text { spp (n=4) }\end{array}$ \\
\hline Amikacin & $(2) 15.3 \%$ & $(5) 41.6 \%$ & $(6) 25 \%$ & $(1) 14.3 \%$ & $(1) 25 \%$ \\
\hline Ampicillin & 0 & 0 & - & 0 & 0 \\
\hline Aztreonam & - & - & $(6) 25 \%$ & - & - \\
\hline Cefepime & 0 & $(1) 8.3 \%$ & $(10) 41.66 \%$ & $(1) 14.3 \%$ & $(2) 50 \%$ \\
\hline Cefotaxime & 0 & $(1) 8.3 \%$ & - & $(1) 14.3 \%$ & - \\
\hline Ceftazidime & - & - & $(7) 29.16 \%$ & - & - \\
\hline $\begin{array}{l}\text { Cefoperazone+ } \\
\text { Salbactam }\end{array}$ & $(6) 46.1 \%$ & $(5) 41.6 \%$ & $(10) 41.66 \%$ & $(3) 42.8 \%$ & $(1) 25 \%$ \\
\hline Ciprofloxacin & & & & & \\
\hline Cotromox/TMP & $(3) 23.6 \%$ & $(5) 16.6 \%$ & $(5) 20.8 \%$ & 0 & $(1) 25 \%$ \\
\hline Gentmycin & $(4) 30.7 \%$ & $(6) 50 \%$ & - & 0 & $(1) 25 \%$ \\
\hline Imepenem & - & - & - & $(1) 14.3 \%$ & $(1) 25 \%$ \\
\hline Piperacillin/ Tazobactam & $(6) 46.7 \%$ & $(9) 75 \%$ & $(10) 41.66 \%$ & - & - \\
\hline Tobramycin & - & - & $(10) 41.7 \%$ & - & $(7) 100 \%$ \\
\hline Tetracyclin -E & $(4) 30.7 \%$ & $(6) 50 \%$ & - & 0 & $(2) 50 \%$ \\
\hline Meropenem & $(9) 69.2 \%$ & $(9) 75 \%$ & - & $(6) 85.7 \%$ & $(3) 75 \%$ \\
\hline Tigecycline & $(13) 100 \%$ & $(10) 83.3 \%$ & - & $(5) 71.4 \%$ & $(4) 100 \%$ \\
\hline Polymixin-B & $(13) 100 \%$ & $(13) 100 \%$ & $(24) 100 \%$ & 0 & $(4) 100 \%$ \\
\hline Colistin & $(13) 100 \%$ & $(13) 100 \%$ & $(24) 100 \%$ & 0 & $(4) 100 \%$ \\
\hline
\end{tabular}

Table 5 Antibiotic Sensitivity of Gram Positive Organisms

\begin{tabular}{|l|c|c|}
\hline Antibiotics & $\begin{array}{c}\text { Staphylococcus } \\
\text { aureus (n=16) }\end{array}$ & $\begin{array}{c}\text { Enterococcus } \\
\text { species(n=5) }\end{array}$ \\
\hline Ampicillin & $(4) 25 \%$ & $(1) 20 \%$ \\
\hline Cefepime & $(10) 62.5 \%$ & 0 \\
\hline Ciprofloxacin & $(2) 12.5 \%$ & 0 \\
\hline Clindamycin & $(7) 43.7 \%$ & $(2) 40 \%$ \\
\hline Cotimox/TMP & $(6) 37.5 \%$ & $(1) 20 \%$ \\
\hline Piperacillin-tazobactam & $(10) 62.5 \%$ & 0 \\
\hline Erythromycin & $(2) 12.5 \%$ & $(2) 40 \%$ \\
\hline Gentamycin & $(11) 68.7 \%$ & $(2) 40 \%$ \\
\hline Tecoplanin & $(14) 87.5 \%$ & 0 \\
\hline Cephoxitin & $(9) 56.2 \%$ & $(1) 20 \%$ \\
\hline Doxycillin & $(15) 93.7 \%$ & $(3) 60 \%$ \\
\hline Linezolid & $(13) 81.2 \%$ & $(5) 100 \%$ \\
\hline Vancomycin & $(16) 100 \%$ & $(5) 100 \%$ \\
\hline
\end{tabular}

Table 6 Magnitude of infection by Multidrug resistant organisms (MDRO'S) like Extended spectrum beta lactamase and Methicillin- resitant Staphylococcus aureus

\begin{tabular}{|l|c|c|}
\hline MDRO & Number of isolates & Percentage (\%) \\
\hline Present & 80 & 88.89 \\
\hline Absent & 10 & 11.11 \\
\hline Total & 90 & 100.00 \\
\hline
\end{tabular}

\section{Discussion}

Severe DFIs are usually polymicrobial in nature, where as mild and moderate DFIs are mostly monomicrobial $^{13}$. Our study presents a comprehensive clinical and microbiological profile of infected diabetic foot ulcers, especially by multidrug-resistant organisms. Appropriate selection of antibiotics based on the anti-biograms of the isolates from the lesions is most critical for the proper management of these infections.

In this study, samples from 73 cases were taken out of which 3 samples were sterile and 5 samples were contaminated, Potent pathogens were grown in 65 patients sample out of which $42(64.61 \%)$ 
showed monomicrobial and 23(35.38\%) showed polymicrobial growth. We found high rate of mono-microbial growth $(64.61 \%)$ as compared to polymicrobial growth $(35.38 \%)$. Our findings are in concordance with Sudhir $\mathrm{K}$ et $\mathrm{al}^{5}$ and Jitendranath $\mathrm{A}$ et $\mathrm{al}^{3}$ who also reported high rate of mono-microbial growth as compared to polymicrobial growth. However Umadevi .S et $\mathrm{al}^{14}$ and Saseedharan $\mathrm{S}$ et al ${ }^{15}$ reported high rate of polymicrobial growth as compared to monomicrobial growth.

The monomicrobial nature of infection is associated with the duration of the ulcer and antimicrobial treatment. Earlier in the infection, the monomicrobial state prevails and as the infection progresses with time, a polymicrobial state arises.

In this study we found that the age group most commonly affected by the diabetic foot ulcer was $51-60$ years $(46.15 \%)$, followed by 61 or more years $(32.30 \%)$ which is consistent with the study conducted by Jitendranath et al ${ }^{3}$, P. Ramakant et $\mathrm{al}^{13}$, Khare at $\mathrm{al}^{16}$ and Patil .S et $\mathrm{al}^{17}$ who also reported the same findings. The number affected increases in elderly age group and less common in younger age group.

In this study most cases of diabetic foot ulcer were of 4-8 weeks duration i.e 30 cases $(46.15 \%)$ followed by 2-3 weeks in 21 cases(32.30\%). Most commonly right foot was involved. Our results are concordance with Khare $\mathrm{J}$ et $\mathrm{al}^{16}$ and Katherivel $\mathrm{M}$ et $\mathrm{al}^{18}$ who also reported most cases of diabetic foot ulcer were of 4-8 weeks duration.

In this study maximum no. of cases were observed in Grade 2 of diabetic foot ulcer(36.9\%) followed by Grade $3(24.6 \%)$ which is similar with the study conducted by Jitendranath $\mathrm{A}_{\text {et }} \mathrm{al}^{3}$ Khare et $\mathrm{al}^{16}$, Ramakant $\mathrm{P}$ et $\mathrm{al}^{13}$ who reported maximum cases of grade 2 of diabetic foot ulcer in $40 \%$, $36 \%, 35.5 \%$ respectively. However Patil S et al ${ }^{17}$ reported $60 \%$ in Grade 2 of diabetic foot ulcer.

We also observed that maximum monomicrobial growth was isolated from grade 2 followed by grade 3 as the grade progresses polymicrobial wound infection was found to be more common. It can be interpreted that to start with, there is a poor response to injury in a patient with diabetes. This may be because of several factors like vascular insufficiency, neuropathy and poor diabetic control. The poor defence leads to a rapid increase in the number of microbes, with progressive deterioration of diabetic foot wound.

In this study Pseudomonas species(25.65\%) was predominant among gram negative bacilli and Staphylococcus aureus (16.84\%) was the predominant among gram positive cocci .Our results are consistent with study conducted by Ramakant et $\mathrm{al}^{13}$, Mehta et $\mathrm{al}^{19}$, Turhan et al ${ }^{20}$ in which Pseudomonas was the commonest organism isolated. However Chittur $\mathrm{R}$ et $\mathrm{al}^{7}$ reported Proteus species (24.26\%) as a predominant among gram negative bacilli in their study. Majority of Pseudomonas species were isolated from grade 2 and grade 3 diabetic foot ulcers. Staphylococcus aureus (16.84\%) was the second most common organism isolated in our study, majority of them were from grade 1 and grade 2 diabetic foot ulcers which are usually uncomplicated ulcers.

In this study, out of 90 isolates 80 were resistant to 3 or more classes of drugs which accounts for $88.8 \%$ of MDRO which is in accordance with the study of Sudhir $\mathrm{K}$ et $\mathrm{al}^{5}$ and Banu $\mathrm{K}$ et $\mathrm{al}^{4}$ who have reported $91 \%$ and $97.6 \%$ of MDRO's respectively. Multidrug resistance was predominantly seen in Acinetobacter spp, Proteus spp and Enterobacter species. Similar results were seen in study of Sudhir K et $\mathrm{al}^{5}$ and Yerat $\mathrm{R}$ et $\mathrm{al}^{7}$. Factors responsible for MDR may be frequent hospitalization, recent use of broad-spectrum antibiotics, inadequate surgical source reduction, chronic wounds, irrational use of antibiotics, and the transfer of resistance genes by transport means.

In this study $43.7 \%$ of Methicillin resistant Staphylococcus aureus was reported which is similar with the results of Sudhir K et $\mathrm{al}^{5}$, Yerat $\mathrm{R}$ et $\mathrm{al}^{7}$, Turhan et $\mathrm{al}^{20}$ and Rawat $\mathrm{V}$ et $\mathrm{al}^{21}$ reported $41 \%, 40 \%, 44.2 \%$ and $40 \%$ respectively. 
We also found $24.6 \%$ of ESBL producers in our study which is similar with the study conducted by Shanmugam et $\mathrm{al}^{22}$ and Turhan et $\mathrm{al}^{20} 15 \%$ and $13.2 \%$ respectively.

In this study all Pseudomonas spp were sensitive to Colistin(100\%), while few of them were sensitive to Cefepime (42.66\%), Cefoperazon+ Salbactam (42\%) and Tobramycin(42\%) which is consistent with the study of Sudhir $\mathrm{K}$ et $\mathrm{al}^{5}$ and Deepa $\mathrm{T}$ et $\mathrm{al}^{6}$.

In this study most of the Enterobacter spp and Escherichia coli were sensitive to Polymixin $\mathrm{B}(100 \%)$, Tigecyclin (100\%) and Meropenem (69.2\%) while most of them were resistant to Penicillin, Quinolones and Cephalosporins. Similar results were reported by Sudhir K et $\mathrm{al}^{5,}$ Khare $\mathrm{J}$ et $\mathrm{al}^{16}$ and Turhan $\mathrm{V}$ et $\mathrm{al}^{20}$.

In this study Staphylococcus aureus were sensitive to Vancomycin(100\%), Linezolid (89.2\%), Doxycilin(93.7\%) and Tecoplanin $(87.5 \%)$. Vancomycin and Linezolid were the most effective antibiotics against gram positive organisms. Similar results were reported by Sudhir $\mathrm{K}$ et $\mathrm{al}^{5}$, Khare $\mathrm{J}$ et $\mathrm{al}^{16}$ and Turhan $\mathrm{V}$ et $\mathrm{al}^{20}$. Among the Staphylococcus aureus, $43.7 \%$ were MRSA. Our result was similar to the study of Sudhir $\mathrm{K}$ et $\mathrm{al}^{5}$, Yerat $\mathrm{R}$ et $\mathrm{al}^{7}$, Turhan et $\mathrm{al}^{20}$ and Rawat $\mathrm{V}$ et $\mathrm{al}^{21}$ where MRSA were reported $41 \%, 40 \%, 44.2 \%$ and $40 \%$ respectively. The MRSA displayed high level of resistance to Erythromycin (88\%), Penicillin (75\%) and Quinolones (88\%).

This study presents a comprehensive clinical and microbiological profile of infected diabetic foot ulcers, especially by multidrug-resistant organisms. Appropriate selection of antibiotics based on the anti-biograms of the isolates from the lesions is most critical for the proper management of these infections.

\section{Conclusion}

Diabetic foot ulcers are one of the most common and dreaded complications of diabetes. Thus it is utmost important to screen all elderly patients for diabetes and educate them about foot care. Early identification of the risk factors and timely institution of appropriate treatment indispensable to avoid amputations. Clinicians should switch to culture report-based use of narrower spectrum therapy. This would improve the overall antibiotic efficacy and reduce the emergence of multidrug resistant organisms in diabetes.

\section{References}

1. B A Bulolo, M A Pase and F Ginting. Antibiotic sensitivity pattern of bacteria from diabetic foot infections Haji Adam Malik central general hospital. IOP Conf. Series: Earth and Environmental Science 125 (2018) 012052.

2. Syeda Sadia Amjad, Jamal Zafar, Nadia Shams Bacteriology of diabetic foot in tertiary care hospital; frequency, antibiotic susceptibility and risk factors. J Ayub Med Coll Abbottabad 2017;29(2)

3. Jitendranath A, Hegadi S, Bhai G, Bhargavi L, Ramani Bai and $\mathrm{T}$. Vishu.Bacteriological Profile of Diabetic Foot in a Tertiary Care Centre in Trivandrum, India. International Journal of Current Microbiology and Applied Sciences 2016;5(6):279-86.

4. Asima Banu, Mir Mohammad Noorul Hassan, Janani Rajkumar, Sathyabheemarao Srinivasa. Spectrum of bacteria associated with diabetic foot ulcer and biofilm formation: A prospective study AMJ 2015;8(9):280-5

5. Sudhir K. Jain, Rashmisnata Barman1. Bacteriological Profile of Diabetic Foot Ulcer with Special Reference to Drug- resistant Strains in a Tertiary Care Center in North- East India. Indian Journal of Endocrinology and Metabolism. 2017;21(5):

6. Deepa T, T. Kasturi, G. Avinash*, P. Muni lakshmi, P. Sreenivasulu reddy, K. Jithendra, and T. Ravi kumar. Bacteriological Profile in Patients with Diabetic Foot Ulcers with special 
reference to their antibiotic sensitivity pattern Int. J. Curr. Microbiol. App. Sci 2015;4(3):706-12

7. Ranjini Chittur Yerat, Vidhya Rani Rangasamy. A clinicomicrobial study of diabetic foot ulcer infections in South India. International Journal of Medicine and Public Health 2015;5(3):1-4

8. Shalbha Tiwari, Daliparthy D. Pratyush, Awanindra Dwivedi, Sanjiv K. Gupta, Madhukar Rai, Surya K. Singh. Microbiological and clinical characteristics of diabetic foot infections in northern India. J Infect Dev Ctries 2012;6(4):32932.

9. A.W. Bauer, W. M. Kirby, J. C. Sherris, and M. Turck, "Antibiotic susceptibility testing by a standardized single disk method," American Journal of Clinical Pathology. 1966;45(4):493-6

10. Clinical and Laboratory Standards Institute (CLSI), "Document M100-S17. Performance standards for antimicrobial susceptibility testing," CLSI, 940 West Valley Road, Suite 1400, Wayne, Pennsylvania 19087-1898, USA, 2007.

11. Chaudhary U, Aggarwal R. Extended spectrum beta lactamases (ESBL)- an emerging threat to clinical therapeutics. IJMM, 2004;22(2):75-80

12. Cauwelier B, Gordts B, Descheemaecker $\mathrm{P}$, Van Landuyt H. Evaluation of a disk diffusion method with cefoxitin (30 mu g) for detection of methicillin-resistant Staphylococcus aureus. European Journal of Clinical Microbiology \& Infectious Diseases. 2004;23:389-92

13. P. Ramakant \& A. K. Verma \& R. Misra \& K. N. Prasad \&G. Chand \& A. Mishra \& G. Agarwal \& A. Agarwal \& S. K. Mishra. Changing microbiological profile of pathogenic bacteria in diabetic foot infections: time for a rethink on which empirical therapy to choose? Article in Diabetologia $\cdot$ September 2011.
14. Sivaraman Umadevi, Shailesh Kumar, Noyal Mariya Joseph, Joshy M Easow, G Kandhakumari, Sreenivasan Srirangaraj, Sruthi Raj, Selvaraj Stephen. Microbiological study of diabetic foot infections. Indian Journal of Medical Specialities 2011;2(1):12-7.

15. Sanjith Saseedharana,, Manisa Sahub, Roonam Chaddhaa, Edwin Pathrosea, Arun Balc, Pallavi Bhalekarc, Priyadharshini Sekard, Padma Krishnand. Epidemiology of diabetic foot infections in a reference tertiary hospital in India. Brazilian journal of microbiology 2018; 49:401-6.

16. Jaideep Khare, Prachi Srivastava, Jalaj Khare, Jyoti Wadhwa, Prasun Microbiological Profile of Diabetic foot Ulcers Experience from a Tertiary care centre in South India. International Journal of General Medicine \& Surgery. Int J Gen Med Surg 2017;1(2):109

17. Swati V. Patil, Roshan R. Mane. Bacterial and clinical profile of diabetic foot ulcer using optimal culture techniques. International Journal of Research in Medical Sciences Patil SV et al. Int J Res Med Sci. 2017;5(2):496-502.

18. Kathirvel M, Prabakaran M, Jayarajan J, Sivakumar A, Govindan V. Risk factors for the diabetic foot infection with multidrug-resistant microorganisms in South India. International Surgery Journal 2018;5(2):1-5

19. Vaidehi J. Mehta*, Kunjan M. Kikani, Sanjay J. Mehta. Microbiological profile of diabetic foot ulcers and its antibiotic susceptibility pattern in a teaching hospital, Gujarat. International Journal of Basic \& Clinical Pharmacology | JanuaryFebruary 2014;3(1):1-3

20. Vedat Turhan, Mesut Mutluoglu, Ali Acar1, Mustafa Hatipoğlu, Yalçın Önem, Gunalp Uzun, Hakan Ay, Oral Öncül, Levent Görenek. Increasing incidence of 
Gram-negative organisms in bacterial agents isolated from diabetic foot ulcers. J Infect Dev C tries 2013;7(10):707-12.

21. Rawat V, Singhai M, Kumar A, Jha P, Goyal R. Bacteriological and Resistance Profile in Isolates from Diabetic Patients. North American Journal of Medical Sciences 2012;4(11):1-4.

22. Priyadarshini Shanmugam, Jeya M, Linda Susan. The Bacteriology of Diabetic Foot Ulcers. With a Special Reference to Multidrug Resistant Strains. Original article

DOI: 10.7860/JCDR/2013/5091.2704. 